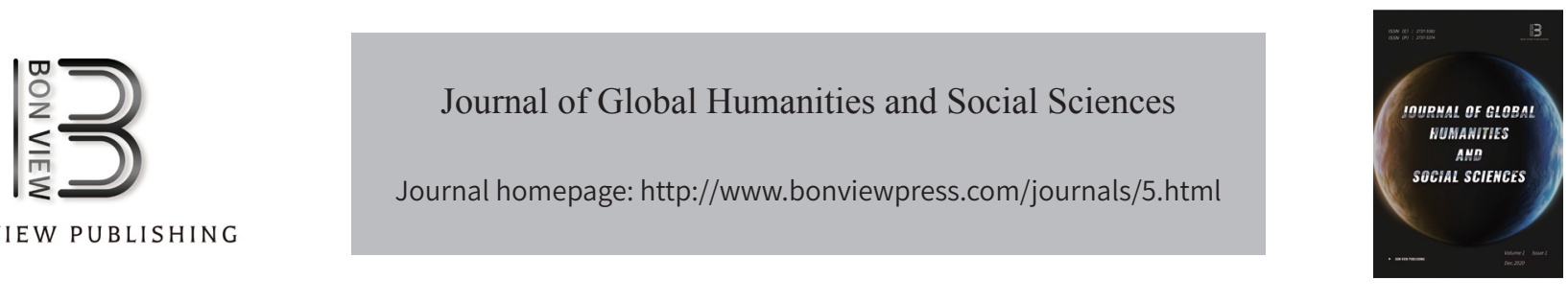

\title{
Analysis on the Key Points of Information Teaching Design Results in Architectural Teaching
}

\author{
Chen Jiahui \\ Chinese Academy of Fine Arts, Hangzhou, Zhejiang ,310024,China
}

\begin{abstract}
As we all know, information teaching design belongs to the product of the application of modern educational technology theory, and its core lies in solving the difficult problems existing in teaching activities through multimedia technology and network technology.As far as the actual situation is concerned, the emergence of information teaching design has caused a certain impact on the traditional teaching mode.Therefore, information teaching design has become an important educational method for college teachers. The teaching practice shows that the introduction of information teaching design into the teaching of architecture is helpful to promote the high quality of teaching activities and to improve students' interest in learning.Based on this, this paper will take the concept and design of information teaching design as the starting point, and then discuss it around it, in order to give some reference to the majority of colleagues.
\end{abstract}

Key words: informationization; teaching design; architecture teaching; analysis

Education is a century-old plan for the development of a country and a nation, and the implementation of innovative education is an important guarantee for cultivating high-quality innovative talents and building a cultural power.It is under the background of the development of this era that the introduction of information teaching design results in the process of teaching activities of architecture specialty becomes an important guarantee to promote the development of teaching 
activities. Therefore, teachers majoring in architecture in contemporary colleges and universities should take teaching practice as the basic starting point, deeply explore the results of information teaching design, and take this as the basis to improve the teaching level and enable students to master knowledge better. Let students like the classroom more, and then promote the long-term development of education.

\section{Concept and Design of Information Teaching Design}

Information teaching, as its name implies, refers to a bilateral educational activity carried out by educators and learners through the integration of contemporary educational media, educational technology and information resources.Its most remarkable characteristic is to regard information technology as a kind of support and modern education and teaching theory as a kind of guidance.In the concrete application of the results of information-based teaching design, it is necessary to create a new teaching model structure, and in the teaching content, the content covered by information-based teaching design includes extremely rich teaching content, and it also has the characteristics of times and richness. Therefore, information teaching itself is very suitable for students' learning characteristics and requirements. Therefore, information-based teaching design is not only a change of methods, but also a teaching system based on modern information technology ${ }^{[1]}$.

The design of information-based teaching was first put forward by Professor Li Thicken. When he put forward this idea, he clearly pointed out that it is necessary to continuously integrate and utilize information technology and information resources to innovate the existing teaching mode through systematic methods, taking learning as the center.And this innovation will cover every link of teaching, so as to realize the optimization and innovation of existing teaching.Specifically, through the application of information teaching design, the creation of information environment, and then rely on the information environment itself to obtain and use information resources.In this process, through the application of this model, students' autonomous learning and inquiry ability will be improved, at the same time, students' information literacy and learning interest will be increased accordingly, and then the purpose of optimizing the whole teaching will be achieved.

\section{The Types of Information Teaching Resources and the Core Principles of Information}

\section{Teaching for Architectural Specialty}

According to the present situation, in the process of information teaching design and application, four types of information teaching resources teaching resources, including analog audio-visual teaching materials, digital audio-visual teaching materials, multimedia teaching software and electronic 
publications. The first is the simulation audio-visual teaching material, this kind of teaching resources mainly includes the projection teaching material slide, the audio-visual teaching material and so on, which is usually used in the student's classroom teaching. Secondly, digital audio-visual teaching materials, including $\mathrm{CD} 、 \mathrm{VCD}$, this type of teaching materials with the development of Internet technology, has been hard to find.Then there is multimedia teaching software, which is mainly a kind of teaching resource with computer technology as the core.Finally, electronic publications, including books, publications and newspapers, are mainly used for students' self-study after class.

Teaching practice shows that in the process of teaching construction specialty, if we want to ensure that the advantages of information teaching design can be carry out relevant teaching activities in accordance with some basic principles.Teaching practice shows that in the process of teaching construction specialty, if we want to ensure that the advantages of information teaching design can be carry out relevant teaching activities in accordance with some basic principles.At the same time, teachers, as promoters of teaching, should also supervise the learning process of students through monitoring, guiding and evaluating students.Secondly, in the process of professional teaching based on the method of information teaching design, we should also pay attention to the application of all kinds of information resources, so as to make the best use of information resources, and then promote the development of teaching activities.

In addition, in the process of information teaching of architecture specialty, we should carry out teaching activities with the main line of "task driven" and "problem solving ", so that students can learn under the leadership of the main line. Then improve the purpose and efficiency of students.In addition to the above two points, we should pay close attention to the principle of "cooperative learning “, which includes not only the traditional cooperation between students and students, but also the cooperation between teachers and even interdisciplinary cooperation.Finally, this teaching model also emphasizes the evaluation of students' learning resources and learning process, that is, to promote the transformative development of teaching model through evaluation, so as to solve the problems existing in the process of combining theory with practice in time ${ }^{[2]}$.

\section{Prerequisites for the Design of Information Technology for Architectural Specialty}

\section{Teaching}

A. Improving the Information Teaching System

In the process of perfecting and promoting the application of information teaching design in architecture specialty, teachers should devote themselves to improving the ability of applying 
contemporary information technology, and pay attention to the rationality of the application of methods. In order to ensure the efficiency of classroom teaching.In this process, in addition to the efforts of teachers, schools should also strive to promote the improvement of information teaching system. Therefore, the school should try to rely on the local area network to build the corresponding network classroom, and can try to build independent learning website, intelligent classroom, so as to improve the level of information.In addition to improving the hardware level, we should try to improve the software level of architecture teaching, so as to promote and provide solid support for information teaching design.

B. Creating a Teaching Resource Platform

Before the application teaching activities of information design, the school should strengthen the construction of learning and teaching resource platform, so that professional teachers can effectively share the achievements of others in the process of developing courseware.Moreover, in the process of construction, the school should also devote itself to the development of the subject website of architecture specialty, which aims to promote and promote the communication between teachers and students, and provide a good platform for their communication. In order to provide a supplement to classroom teaching.In addition, teachers can also establish a corresponding small teacher-student communication platform through other Internet platforms, so that the communication between teachers and students can break the space limit. Finally, the download module of learning resources should be created to facilitate students to download teaching resources ${ }^{[3]}$.

C. Provision of information teaching services

Information technology itself belongs to an advanced and complex technology, and information technology also integrates many advanced technologies.Looking at the development of information technology from the perspective of the development of the times can be found that information technology is developing at an amazing speed.It is in this case that it is actually difficult for teachers to master all the information technology content in a short time.Therefore, the school can mobilize information technology personnel to set up a special group to apply information technology to teachers, and on this basis, to do a good job of specific technical services, so as to help construction teachers solve the difficult problems in teaching. At the same time, the school can also publish the cases and skills of information technology application through the campus network, so as to promote the overall improvement of information teaching level.

IV. Application Advantage of Information Design Teaching for Architectural Specialty in Classroom Teaching 
A. Optimizing learning environment and improving teaching flexibility

Using the method of information design teaching to carry out the teaching of architecture specialty can optimize the learning environment of students.In the middle, the information technology itself audio-visual combination, the characteristics of sound and dynamic, so that the appeal of teaching activities itself has been significantly enhanced. This has led to a major change in the previous relatively fixed teaching classroom, and made the teaching activities themselves rich and colorful.In addition, with the application of information design results, the interest of teaching can also be significantly improved, so that students' enthusiasm for learning has been greatly improved, and students can be more active and involved in teaching activities.It should also be pointed out that this teaching method can also improve students' perceptual understanding of theoretical knowledge and ensure the effect of teaching ${ }^{[4]}$.

In addition, using the method of information design to teach architecture specialty can also improve the flexibility of teaching. In the middle, teachers can realize individualized teaching according to the design of information teaching, so that the teaching activities themselves can be closer to the students' learning practice, so as to truly achieve the purpose of teaching students according to their aptitude.Moreover, the use of information design can also enable learners to fully combine their own individual differences, thus promoting the improvement of learning efficiency.

B. Promote the formation of interactive learning atmosphere, can ensure the comprehensiveness of information

The use of information design for teaching activities can form an interactive learning atmosphere, students through the Internet platform for information interaction, can make the teaching itself form a good learning atmosphere.Moreover, the interaction through information technology can also break the limitation of space and make teaching not limited to classroom.In addition, the use of information technology design to carry out professional teaching, but also to ensure the comprehensiveness of information.As we all know, information resources themselves have a certain breadth and depth, and after the development of teaching activities, teachers through this characteristic, expand the learning space of students, so that students can immerse in the ocean of knowledge $\mathrm{e}^{[5]}$.

C. Adopt different teaching methods according to different teaching requirements

Through the scientific application of information technology design, it can meet various teaching requirements, and the results of information technology design enrich the existing teaching methods. In the middle, teachers can adopt comprehensive demonstration teaching according to teaching requirements, and can also use experimental operation teaching and so on.Moreover, the construction specialty teaching supported by information technology can also easily show the macro teaching 
content, and can also show the extremely abstract teaching content and so on.It can be seen that teaching based on information technology can provide many paths for teaching activities themselves, which provides good support for the improvement of teaching efficiency ${ }^{[6]}$.

\section{Conclusion}

In a word, with the continuous promotion of education in China in recent years, the teaching methods and models have been widely concerned.It is under this background that contemporary architecture teachers should take teaching practice as the starting point, pay attention to the introduction of information teaching design results, and combine theory with practice. The results of information teaching design can better promote the teaching level of architecture and the long-term development of higher education in China.

\section{References}

[1]Zhen Zhang, Wen Ma. Discussion on the Application of Information-based Teaching Design Method in Architectural Specialty Teaching [J].]; and Engineering Technology and Management (English)2(3):82-83.

[2]Zhen Zhang, Wen Ma. Discussion on the Application of Information-based Teaching Design Method in Architectural Specialty Teaching [J].]; and Engineering Technology and Management (English)2(3):82-83.

[3]Zhen Zhang, Wen Ma. Discussion on the Application of Information-based Teaching Design Method in Architectural Specialty Teaching [J].]; and Engineering Technology and Management (English)2(3):82-83.

[4]Wang Jiyu. Analysis on Teaching Design of Architectural Design Course under the J]. of Information Technology Tomorrow's fashion 2020(5):14-16.

[5]Lingzhi Hong. Discussion on the Connotation and Key Points of Information Teaching Design [J].] in Brief Science and Technology Innovation Bulletin 15(36):200 202.

[6]Huang Tiyun. Analysis and Research on Information-based Teaching Design and Classroom Construction [J].]; and Think tank era ,2018,140(24):179-180. 